\title{
O PROCESSO DE SUCESSÃO NAS EMPRESAS FAMILIARES: UM ESTUDO FEITO EM EMPRESAS FAMILIARES DA REGIÃO DO SUL DE SANTA CATARINA
}

DOI: 1014211/Rege33143

Artigo recebido em:10/06/2015

Artigo aprovado em:14/12/2014

\author{
Juliana D’Agostin Batista - Universidade do Extremo Sul Catarinense 1 \\ Gisele Silveira Coelho Lopes - Universidade do Extremo Sul Catarinense 2 \\ Melissa Watanabe - Universidade do Extremo Sul Catarinense 3 \\ Izabel Regina de Souza - Universidade do Extremo Sul Catarinense4
}

Resumo: Este estudo revela a história de quatro empresas familiares localizadas no Sul de Santa Catarina. Foram entrevistados os sucessores, cuja temática destaca desde o momento em que o fundador decide iniciar o próprio negócio, até o momento que ocorre a sucessão. A pesquisa foi realizada por meio de entrevistas, gravadas e transcritas, respeitando a autenticidade das falas dos participantes. $O$ presente trabalho tem caráter descritivo com abordagem de análise qualitativa. $O$ foco da entrevista foi o processo sucessório, cujo objetivo foi compreender como aconteceu o processo sucessório em empresas familiares do extremo sul catarinense. Foram selecionados por acessibilidade, 2 (duas) empresas do segmento gráfico e 2 (duas) empresas do segmento do vestuário. A análise dos resultados pôde delinear que os processos aconteceram sem planejamento explícito dos seus fundadores, sendo que os escolhidos para administrar as empresas foram os filhos homens, por estarem na empresa com o fundador desde pequenos.

Palavras-Chave: Empresas Familiares; Processo de Sucessão; Sucessão Familiar.

\section{THE SUCCESSION PROCESS IN FAMILY BUSINESS: A STUDY IN THE SOUTH OF SANTA CATARINA, BRAZIL}

\begin{abstract}
This study reveals the story of four (4) family business located in the South of Santa Catarina. Successors were interviewed, whose theme highlights from the moment that the founder decides to start his own business, until such time that the succession occurs. The survey was conducted through interviews, recorded and transcribed, respecting the authenticity of participants' speech. The present study is descriptive with qualitative analysis approach. The focus of the interview was the succession process, whose goal was to understand how it happened the succession

\footnotetext{
1 E-mail: ju.dagostin@hotmail.com

2 E-mail: giselelopes@unesc.net Endereço: Rua Alameda Felipe Arns, 210 - Edifício Mosel - Apto. 608 - Forquilhinha - Centro - 88850-000 - Santa Catarina

3 E-mail: melissawatanabe@unesc.net

4 E.mail: izabelrsouza@gmail.com
}

BATISTA, J. D. et al. O processo de sucessão nas empresas familiares: um estudo feito em empresas familiares da Região do Sul de Santa Catarina. Revista de Empreendedorismo e Gestão de Pequenas Empresas, v.4, n.3, 2015. 
process in family businesses from the southern end of Santa Catarina. Were selected for accessibility, two (2) companies in the printing segment and two (2) companies in the apparel segment. The results could delineate the processes that happen in a natural way without planning by its founders, and to administer the chosen companies were the sons, being in company with the founder from small.

Keywords: Family Business; Succession Process; Succession Family.

\section{Introdução}

Sabe-se que as empresas familiares estão presentes em diversos setores da economia brasileira. Dados do Instituto Brasileiro de Geografia e Estatística (IBGE, 2003) apontam que a maioria das empresas familiares $(58,9 \%)$ atuam no ramo alimentício, seguido de comércio de produtos variados (papelarias, confecções, artigos de informática, etc.). Independente de qual seja o ramo da empresa ou até mesmo o porte, todas são indispensáveis para o crescimento da economia de um país Para reforçar esta ideia, Lethbridge (1997) defende que as empresas familiares fazem parte de pelo menos dois terços do PIB, além de gerar mais da metade das vagas de emprego.

Durante muitos anos, as empresas familiares foram motivo de preconceito. Acreditava-se que o que mais importava na gestão eram os laços familiares e não a competência. Porém, após os anos de 1990, os empresários encontraram maneiras mais eficientes de melhorar a convivência com os sócios, além de conservar a boa gestão (ATTUCH, 2007).

Apesar das melhorias apontadas por Attuch (2007), ainda observa-se que a empresa familiar apresenta dificuldades para a sua sobrevivência no mercado. A cada 100 empresas, apenas 30\% passaram para a segunda geração e somente 10\% chegam até a terceira geração (VENTURA, 2006).

Nessa linha, é possível dizer que a falta de planejamento no processo sucessório seria uma causa possível que justifica as diversas empresas familiares a não conseguirem permanecer no mercado. Dependendo da maneira que este plano é conduzido, pode acarretar em vantagens ou desvantagens. Essas consequências, se não forem bem planejadas, poderão levar a empresa à falência.

Para que isso não venha acontecer, há a necessidade de organizar um planejamento de sucessão, de forma gradativa e planejada, que ocorra, a priori, a BATISTA, J. D. et al. O processo de sucessão nas empresas familiares: um estudo feito em empresas familiares da Região do Sul de Santa Catarina. Revista de Empreendedorismo e Gestão de Pequenas Empresas, v.4, n.3, 2015. 
troca de poder (SOUSA, 2012; JAMES, 2003; LEMOS, 2003; LEONE, 1991) e que tanto sucessor como a família estejam preparados para esta transição (NOVELLINO, 2010; LEONE, 2005; RODRIGUES; RESENDE; PILATTI, 2004).

Vale ressaltar, que os gestores das empresas familiares que chegaram até a segunda geração, possuíam determinadas características, conhecidas como ousadia e espírito empreendedor para dar continuidade ao negócio familiar, sem perder a competitividade no mercado (GRZYBOVSKI; TEDESCO, 1998). Para completar a ideia de Grzybovski e Tedesco (1998), Donatti (1999) acrescenta que para alcançar bom desempenho no processo sucessório, as empresas adotam um método de gestão, em que ambos, sucedido e sucessor, possuem diretrizes que separam assuntos familiares dos profissionais.

É nesta ordem de ideias, que este trabalho tem por objetivo conhecer como ocorreu o processo sucessório em Empresas Familiares do Sul de Santa Catarina. Portanto, a seguir, será apresentado o referencial teórico, delimitado em duas seções.

Primeiramente, é preciso entender a definição de empresas familiares e também mostrar a importância destas empresas para a sociedade e economia do país. Em seguida, são apresentadas ideias e conceitos sobre como proceder diante dos processos sucessórios e a importância do planejamento diante da sucessão empresarial.

Através de uma pesquisa qualitativa em profundidade, as entrevistas feitas aos sucessores de 4 (quatro) empresas, tinham objetivo de conhecer como aconteceu o processo sucessório, de que maneira foi escolhido o sucessor e se o processo foi planejado pelo fundador.

\section{Empresa familiar}

A empresa familiar pode ser compreendida como um empreendimento cujo responsável pelo poder de gestão está ligado à empresa pelo menos há duas gerações. Isso significa que os familiares possuem poder de influência na definição

BATISTA, J. D. et al. O processo de sucessão nas empresas familiares: um estudo feito em empresas familiares da Região do Sul de Santa Catarina. Revista de Empreendedorismo e Gestão de Pequenas Empresas, v.4, n.3, 2015. 
das metas a serem alcançadas, nos interesses e objetivos da empresa (DONNELLEY, 1964).

Na concepção de Lodi (1987), muitos ainda creem que quando a empresa é familiar, a eficiência é reduzida. Porém, historicamente as empresas familiares bem sucedidas contradizem essa ideia e revelam que a união da família não deprecia a sua eficácia.

Donatti (1999) e mais recentemente Nordqvist et al. (2013) afirmam que a realidade do mercado contemporâneo mostra que a parceria da família pode ter bom desempenho. Vale ressaltar que o resultado negativo não se dá somente pelo fato de familiares fazerem parte da diretoria da empresa, mas sim pela falta de atenção relacionada aos problemas desse relacionamento (DONATTI, 1999).

Freitas e Krai (2010) acrescentam que o profissionalismo e a necessidade de competência para gerenciar são essenciais não apenas para os gestores, mas também para os familiares, fazendo com que o serviço dos profissionais qualificados se torne fundamental para o desempenho da empresa. Para que isso venha acontecer, o gestor precisa considerar primeiramente as habilidades técnicas, a competência e o profissionalismo dos familiares, e não somente os laços de sangue (SOUZA, 2012).

Portanto, para alcançar o bom desempenho empresarial, os executivos precisam manter equilíbrio entre a razão e a emoção (FREITAS; KRAI, 2010). Neste sentido, se a empresa possui uma cultura que condiz com seus valores e princípios, possivelmente será respeitada pelos seus membros e caso ocorra uma gestão de um profissional externo, este deve também entender e respeitar (RICCA, 2012; CASILLAS; VÁZQUEZ; DÍAZ, 2007).

\section{Processo sucessório}

O processo de sucessão permite avaliar a estabilidade da empresa no mercado. Isso significa que quando a empresa iniciou suas atividades era reconhecida como um empreendimento individual. Porém, após a sucessão, passa a ser um negócio familiar (GALLI, 2006). Oliveira (1999) e Duarte e Oliveira (2010) 
destacam sobre a importância de realizar a sucessão de maneira eficiente e planejada, pelo fato de que o mau direcionamento desse processo pode acabar colocando em risco a continuidade da empresa.

No momento em que o atual dirigente da empresa percebe a necessidade de delegar tarefas que exigem maior responsabilidade para uma pessoa de confiança, com objetivo de reduzir a carga horária, até mesmo pela vontade de se afastar do cargo, ele precisa estar preparado para diversas situações. Por isso a necessidade de preparar alguém para assumir a direção e quando essa pessoa estiver pronta para administrar a empresa, será o momento de proceder a sucessão (LANSBERG, 1999).

A consequência do despreparo do processo sucessório pode acabar pondo em risco a estabilidade da empresa, ao deixar tanto a empresa quanto a família vulneráveis a qualquer tipo de risco. Em razão disso, se o processo não for bem planejado, as chances de ambas as partes serem afetadas aumentam (NEVES, 2001). Portanto, a sucessão precisa ser bem delineada, preferencialmente de forma não repentina. O processo requer calma e paciência, podendo levar alguns anos (PETRY; NASCIMENTO, 2009).

É aconselhado realizar a sucessão enquanto o fundador ainda vive, tanto para preparar os sucessores, quanto para discutir sobre a pretensão do novo sucessor para assumir a empresa e a possibilidade de aceitarem serem sócios um do outro. De tal modo que os laços sanguíneos não interfiram nas obrigações da empresa e nem atrapalhe o relacionamento da família. Sendo assim, é importante primeiramente escolher o modelo de sucessão que será implantado na empresa, para posteriormente iniciar o planejamento do processo sucessório (DUARTE; OLIVEIRA, 2010).

A sucessão pode ser efetivada de duas maneiras, o gestor tem a opção de escolher o sucessor entre os familiares ou então contratar um profissional que tenha competência para gerir a empresa, tomando as decisões necessárias para o desenvolvimento do negócio. Os sócios fazem parte do conselho em que é discutida a gestão, sem interferirem nas decisões (GORGATI, 2000).

A melhor maneira para escolher o sucessor é estar ciente das exigências que o cargo de diretor precisa. Desse modo, o julgamento que os familiares farão a 
respeito do sucessor escolhido será baseado apenas nas experiências profissionais, sem qualquer outra interferência (SOUZA, 2012).

Assim, para que a sucessão proceda de maneira tranquila, sem causar transtornos ou perdas para a empresa, Lodi (1987) sugere que a transição comece a ser organizada desde a infância dos filhos, para que não haja imprevistos. Oliveira (1999) ressalta que o processo de sucessão também tem as suas vantagens e desvantagens. Ao mesmo tempo em que o escolhido demonstra interesse em assumir a diretoria, tem competência e habilidade para desempenhar as tarefas delegadas aos diretores da empresa. Ainda assim, pode existir a possibilidade de conflito entre os familiares, pelo direito ao poder da empresa (OLIVEIRA, 1999).

Diferentes mecanismos de treinamento vêm sendo utilizados como forma de preparar os colaboradores para futuramente assumirem a gestão. Esse método é acompanhado pelos familiares de modo que aprovem o sucessor escolhido e que não haja dúvidas e possíveis questionamentos sobre a capacidade do novo herdeiro (SOUZA, 2012).

\section{Procedimentos metodológicos}

O presente estudo foi realizado através de uma pesquisa qualitativa, com caráter exploratório, pois as variáveis de sucessão eram desconhecidas pelos pesquisadores. Segundo Gil (1996), a pesquisa exploratória tem o objetivo de se aprofundar no assunto a fim de adquirir maior conhecimento. Para que o objetivo desta pesquisa fosse alcançado, foi necessário obter informações relevantes que apenas os entrevistados poderiam fornecer.

Este trabalho é resultado de um estudo multicasos (YIN, 2005), pois revela a história de 4 (quatro) empresas familiares localizadas no Sul de Santa Catarina. Foram entrevistados os sucessores destas empresas, abordando desde o momento em que o fundador decide iniciar o próprio negócio, até quando ocorre a sucessão.

Foram selecionados por acessibilidade, 2 (duas) empresas do segmento gráfico e 2 (duas) do segmento do vestuário. A escolha dos entrevistados foi pelo sucessor, por se tratar do condutor atual na gestão da empresa. As empresas foram 
nomeadas como A, B, C e D, como forma de preservar o anonimato, sendo que nas Empresas A, B e D foram entrevistados os Sucessores I e II (filhos) e na Empresa C foi entrevistado o Sucessor I (filho).

O método de coleta dos dados foi um questionário semiestruturado, elaborado pelos pesquisadores, com base no referencial teórico (LODI, 1987; GORGATI, 2000; LEMOS, 2003; RICCA, 2008; LEONE, 2008; OLIVEIRA, 1999; NEVES, 2001), cujas categorias de análise e questões do instrumento estão apresentadas no Quadro 1.

Quadro 1 - Questões utilizadas no instrumento semiestruturado

\begin{tabular}{|c|l|}
\hline $\begin{array}{c}\text { Categorias } \\
\text { de Análise }\end{array}$ & \multicolumn{1}{c|}{ Questões do Instrumento Semiestruturado } \\
\hline $\begin{array}{c}\text { Perfil da } \\
\text { Empresa }\end{array}$ & $\begin{array}{l}\text { A sua empresa já passou por quantos processos sucessórios? A família é constituída } \\
\text { de que forma? Como ocorreu o processo sucessório nesta empresa? } \\
\text { Como é a relação entre família e empresa? Filhos? Parentes? Dentro da empresa. }\end{array}$ \\
\hline $\begin{array}{c}\text { Característic } \\
\text { a do } \\
\text { Fundador }\end{array}$ & Você poderia me descrever as características do fundador desta empresa? \\
\hline $\begin{array}{c}\text { Processo } \\
\text { Sucessório }\end{array}$ & Diante desta história, em sua opinião, o processo sucessório foi planejado ou não? \\
\hline $\begin{array}{c}\text { Escolha do } \\
\text { Sucessor }\end{array}$ & $\begin{array}{l}\text { De que maneira foi realizada a nomeação do sucessor? Qual o critério de escolha? } \\
\text { Compresa? }\end{array}$ \\
\hline $\begin{array}{c}\text { Próximo } \\
\text { Processo } \\
\text { Sucessório }\end{array}$ & $\begin{array}{l}\text { Como a empresa livisão de funções entre irmãos dentro da estrutura organizacional da } \\
\text { Vocêntrada de outros familiares na empres seus filhos deem continuidade aos negócios da família? } \\
\text { A empresa já está se preparando para o processo sucessório da próxima geração? }\end{array}$ \\
\hline
\end{tabular}

Fonte: As autoras (2015).

A pesquisa foi realizada por meio de entrevistas em profundidade, gravadas com duração total, de aproximadamente 160 minutos, e transcritas respeitando a autenticidade das falas dos participantes.

O presente trabalho tem caráter descritivo com abordagem de análise qualitativa. O foco da entrevista foi o processo sucessório, cujo objetivo foi compreender como aconteceu o processo sucessório em empresas familiares do sul catarinense. Foi utilizada a técnica de análise de conteúdo para compreender as opiniões dos sucessores a respeito da temática abordada.

É importante ressaltar que o objetivo do presente estudo não foi o julgamento do certo ou do errado no processo sucessório, mas sim da descrição autêntica de como ocorreu o processo de sucessão em cada empresa. Necessário 
se faz evidenciar que para facilitar a compreensão dos resultados, foi utilizada a categorização dos conteúdos, em que as empresas analisadas foram apresentadas de forma conjunta.

\section{Resultados}

O presente estudo revela a maneira como ocorreu o processo de sucessão em 4 (quatro) empresas familiares, localizadas na região Sul de Santa Catarina (Brasil). Através dos dados obtidos, foi possível aprofundar a história de cada uma das empresas, cujas características se assemelham em vários aspectos, os quais serão apresentados a seguir.

O Quadro 2 apresenta o perfil das empresas e de seus membros. Dentre as 4 (quatro) empresas selecionadas, 2 (duas) - a empresa A e B - atuam no segmento gráfico, enquanto que as empresas C e D atuam no setor de vestuário. Nas empresas B, C e D, o fundador é vivo, porém não trabalha mais na empresa. Já na constituição das famílias apresentam características semelhantes mononucleares, ou seja, Pai, Mãe e Filhos.

Sobre o perfil dos membros que trabalham nas empresas, todos são do gênero masculino. Essa característica indica que as 2 (duas) mulheres das empresas optaram por seguir carreira própria em outras empresas fora do eixo familiar, conforme afirma o Sucessor II da Empresa A: "[...] tenho uma irmã que não faz parte da empresa [...] por opção dela". [grifo nosso]. O Sucessor I da Empresa $B$, também menciona, "[...] uma menina [...] que não tem interesse em trabalhar na empresa [...] tá fazendo artes visuais [...] nada a ver com o nosso negócio." [grifo nosso].

Os sucessores das empresas pesquisadas fazem parte da segunda geração da família. A faixa etária dos gestores varia do mais novo, que administra a empresa C, com 25 anos de idade, ao gestor mais experiente, com 48 anos de idade, que dirige a empresa D. Quase todos sucessores têm o Ensino Superior completo, com exceção do sucessor I da empresa A, que concluiu os estudos até o Ensino Médio.

Quanto à formação dos sucessores, o Sucessor I das empresas $B$ e $D$, junto com o Sucessor II da empresa $A$, tem graduação na área de Administração. Já o 
Sucessor II da empresa B tem formação na área de artes gráficas e o Sucessor II da empresa $D$ tem graduação em contabilidade. Os dois sucessores das empresas $A, C$ e $D$, inclusive o Sucessor I da empresa $B$, assumem o cargo de diretor, apenas o Sucessor II da empresa B não faz parte da diretoria e atua como encarregado na área de produção.

Quadro 2 - Perfil das empresas e dos membros

\begin{tabular}{|c|c|c|c|c|c|}
\hline \multirow{2}{*}{ Variáveis } & \multirow{2}{*}{$\begin{array}{c}\text { Sucessor } \\
\text { es }\end{array}$} & \multicolumn{4}{|c|}{ Empresas e Membros } \\
\hline & & $\mathbf{A}$ & B & C & D \\
\hline Setor & - & Gráfico & Gráfico & Vestuário & Vestuário \\
\hline $\begin{array}{l}\text { Constituiçã } \\
\text { o da } \\
\text { Família }\end{array}$ & - & $\begin{array}{c}\text { Pai (in } \\
\text { memorian) e } \\
\text { Mãe; } 3 \text { filhos. }\end{array}$ & $\begin{array}{l}\text { Pai e Mãe; } 3 \\
\text { filhos. }\end{array}$ & $\begin{array}{l}\text { Pai e Mãe; } 2 \\
\text { filhos. }\end{array}$ & $\begin{array}{l}\text { Pai e Mãe; } 2 \\
\text { filhos. }\end{array}$ \\
\hline Filhos & - & $\begin{array}{l}2 \text { filhos }(M) \text { e } 1 \\
\text { filha }(F) \text { que } \\
\text { optou por não } \\
\text { trabalhar na } \\
\text { empresa. }\end{array}$ & $\begin{array}{c}2 \text { filhos }(M) \text { e } 1 \\
\text { filha }(F) \text { que não } \\
\text { tem interesse em } \\
\text { trabalhar na } \\
\text { empresa. }\end{array}$ & $\begin{array}{l}2 \text { filhos (M), } \\
\text { porém, o filho } \\
\text { mais novo (M) } \\
\text { preferiu } \\
\text { continuar a } \\
\text { faculdade de } \\
\text { biologia. }\end{array}$ & $\begin{array}{c}2 \text { filhos }(\mathrm{M}) ; 1 \\
\text { filho }(\mathrm{M}) \\
\text { trabalha em } \\
\text { outra } \\
\text { empresa do } \\
\text { pai. }\end{array}$ \\
\hline \multirow{2}{*}{ Faixa Etária } & $\mathrm{I}$ & 47 anos & 30 anos & 25 anos & 48 anos \\
\hline & II & 45 anos & 28 anos & - & 45 anos \\
\hline \multirow{2}{*}{$\begin{array}{c}\text { Escolaridad } \\
e\end{array}$} & $\mathrm{I}$ & Ensino Médio & Superior & Superior & Superior \\
\hline & II & Superior & Superior & - & Superior \\
\hline \multirow{2}{*}{ Formação } & 1 & por. & $\begin{array}{c}\text { Administração de } \\
\text { Empresas }\end{array}$ & $\begin{array}{l}\text { Administração e } \\
\text { Comércio } \\
\text { Exterior }\end{array}$ & $\begin{array}{c}\text { Administraçã } \\
\text { o de } \\
\text { Empresas }\end{array}$ \\
\hline & II & $\begin{array}{l}\text { Administração } \\
\text { de Empresas }\end{array}$ & $\begin{array}{l}\text { Artes Gráficas } \\
\text { (São Paulo) }\end{array}$ & - & Contabilidade \\
\hline \multirow{2}{*}{ Geração } & $\mathrm{I}$ & $2^{\mathrm{a}}$ & $2^{\mathrm{a}}$ & $2^{\mathrm{a}}$ & $2^{\mathrm{a}}$ \\
\hline & II & $2^{\mathrm{a}}$ & $2^{\mathrm{a}}$ & - & $2^{\mathrm{a}}$ \\
\hline \multirow{2}{*}{ Gênero } & $\mathrm{I}$ & $\mathrm{M}$ & $\mathrm{M}$ & $\bar{M}$ & $\mathrm{M}$ \\
\hline & II & $\mathrm{M}$ & $\mathrm{M}$ & - & $\mathrm{M}$ \\
\hline \multirow{2}{*}{$\begin{array}{l}\text { Função na } \\
\text { Empresa }\end{array}$} & 1 & $\begin{array}{c}\text { Diretor } \\
\text { Comercial e de } \\
\text { Produção }\end{array}$ & $\begin{array}{c}\text { Diretor } \\
\text { Administrativo } \\
\text { Financeiro }\end{array}$ & Diretor Geral & $\begin{array}{l}\text { Diretor } \\
\text { Comercial }\end{array}$ \\
\hline & II & $\begin{array}{c}\text { Diretor } \\
\text { Administrativo } \\
\text { Financeiro } \\
\end{array}$ & Área de Produção & - & $\begin{array}{c}\text { Diretor } \\
\text { Administrativo } \\
\text { Financeiro }\end{array}$ \\
\hline \multirow{2}{*}{$\begin{array}{l}\text { Experiência } \\
\text { profissional } \\
\text { anterior }\end{array}$} & I & Sim & Não & Não & Não \\
\hline & II & Não & Não & - & Não \\
\hline
\end{tabular}

Legenda: (2 $\left.2^{\mathrm{a}}\right)$ Segunda geração; (M) Masculino; (F) Feminino.

Fonte: As autoras (2015).

Sobre os sucessores terem experiências profissionais antes de assumirem a empresa da família, apenas o Sucessor II da empresa A afirmou ter trabalhado em outra empresa "[...] fui estudar fora durante quatro anos em Florianópolis [...], nesse

BATISTA, J. D. et al. O processo de sucessão nas empresas familiares: um estudo feito em empresas familiares da Região do Sul de Santa Catarina. Revista de Empreendedorismo e Gestão de Pequenas Empresas, v.4, n.3, 2015. 
período eu [...] até trabalhei numa outra empresa [...]" [grifo nosso]. (Empresa A Sucessor II).

\section{Características do fundador}

A história de vida do fundador é sustentada pelas suas características pessoais, os valores defendidos na cultura organizacional que tornam a empresa única e o desempenho da empresa no mercado. Portanto, o sucessor, além de ter a capacidade de dirigir uma empresa, também precisa compreender e respeitar a cultura criada pelo fundador (RICCA, 2012).

O Quadro 3, apresenta as características dos fundadores descritas pelos sucessores de cada empresa.

Quadro 3 - Características dos fundadores

\begin{tabular}{|c|c|}
\hline Empresas & Características do Fundador \\
\hline A & Descentralizador \\
\hline B & Centralizador \\
\hline C & Empreendedor, Descolado \\
\hline D & Líder Nato \\
\hline
\end{tabular}

Fonte: As autoras (2015).

Diante dos adjetivos apresentados no Quadro 3, a característica do fundador da Empresa A foi descentralizador, pois segundo as falas do entrevistado, ele optou pela responsabilidade da área comercial e para as demais áreas, selecionou colaboradores de confiança para assumirem estas responsabilidades.

[...] a empresa iniciou praticamente com ele sozinho [...] não se envolvia com a parte de produção [...] deixava [...] a critério dos próprios funcionários de confiança [...] ele se preocupou mais com a parte comercial [...]. [grifo nosso]. (Empresa A - Sucessor I).

O fato de o fundador ter criado a empresa sozinho, fez com que aprendesse todos os processos que envolvem o andamento do negócio. Após a empresa estar consolidada no mercado, o fundador priorizou se dedicar somente à área comercial, com foco no bom atendimento aos clientes e fornecedores, e na escolha de colaboradores confiáveis para delegar as demais funções. Essa maneira de gerir a empresa é confirmada por Fonseca (2010), que ressalta ser impossível acreditar que

BATISTA, J. D. et al. O processo de sucessão nas empresas familiares: um estudo feito em empresas familiares da Região do Sul de Santa Catarina. Revista de Empreendedorismo e Gestão de Pequenas Empresas, v.4, n.3, 2015. 
uma organização consiga se manter em bom funcionamento sem um líder. Porém, o objetivo das empresas que optam por um comando descentralizado, é incentivar o amadurecimento dos colaboradores para que sejam autônomos, com o reconhecimento da capacidade de gerenciarem o trabalho.

Já na Empresa B, o fundador é caracterizado como sendo centralizador. É o que afirma um dos sucessores: "[...] ele sempre foi muito centralizador [...] tocava tudo sozinho [...] tanto é que essa decisão de passar pra mim ele [...] planejou na cabeça dele e quando chegou a hora [...] ele simplesmente me comunicou". [grifo nosso]. (Empresa B - Sucessor II).

É perceptível pelas falas do entrevistado, que o fundador não tinha o hábito de dividir suas responsabilidades. As ações da empresa eram sempre delineadas por ele mesmo, pois não aceitava a ajuda dos colaboradores, além de não comunicar ou dividir suas ideias com outras pessoas. Este modelo de gestão é defendido por Nunes (2009), quando explica que as atitudes do fundador priorizam os assuntos relacionados ao trabalho, o que acaba provocando intrigas com a família, além de anular a vida social.

Isso acontece quando os líderes não se sentem seguros quanto à competência da equipe ou até mesmo por receio de perder espaço na empresa, fazendo com que outra pessoa do grupo realize o trabalho e se destaque. No caso da Empresa B, o fundador optou por guardar em segredo a escolha que fez em entregar o poder ao filho, comunicando a todos sobre esta decisão apenas no dia em que aconteceu a transição da administração.

O fundador da Empresa $\mathrm{C}$ é descrito como sendo uma pessoa liberal e com um espírito empreendedor. Segundo o sucessor, o fundador sempre expõe suas ideias com objetivo de debater a respeito, ouvindo a opinião dos outros. Trata as pessoas de maneira igual, sem cobrança.

[...] um cara [...] bem descolado e [...] sempre teve uma visão [...] nova bem juvenil, [...] tem a característica de um empreendedor, [...] receptivo às ideias $[. .$.$] nada de rigidez, nada de autoritarismo [...]$ ele dava o exemplo [...]. [grifo nosso]. (Empresa C).

É perceptível que o fundador aparentava ter um estilo mais jovial, dando oportunidade aos colaboradores de apresentar ideias e sugestões de melhorias para a empresa, permitindo que as pessoas vinculadas ao negócio pudessem participar BATISTA, J. D. et al. O processo de sucessão nas empresas familiares: um estudo feito em empresas familiares da Região do Sul de Santa Catarina. Revista de Empreendedorismo e Gestão de Pequenas Empresas, v.4, n.3, 2015. 
ativamente dos projetos. É possível dizer que ele idealizava a perfeição e quando não era alcançada, batalhava até conquistar seu objetivo: o de expandir o negócio.

Este perfil de empreendedor que almeja o sucesso pode ser visto na concepção de Dalbó (2008), quando descreve que o fundador precisa assumir responsabilidades e amar o seu trabalho, indo em busca de aperfeiçoar suas habilidades, sobretudo as menos desenvolvidas. Outra ênfase do perfil empreendedor é a facilidade em perceber a oportunidade de abrir outro negócio.

Com uma característica de liderança, o fundador da Empresa D apresenta uma personalidade forte, pois comandava a empresa com o objetivo de alcançar um bom desempenho. Exigia de seus empregados que se dedicassem ao negócio da mesma maneira com que ele se dedicava. Neste processo não isentou a dedicação dos filhos para as responsabilidades estabelecidas. Por ser filho, tinha que dar o exemplo: "[...] ele é um líder nato [...] tem vocação pra negócio, cobra e sabe cobrar como ninguém, e [...] o horário ele cumpria [...] e cobrava sempre da gente [...] vim de barba feita [...]" [grifo nosso]. (Empresa D - Sucessor II).

Diante destes achados, é possível ainda contribuir que estas atitudes de liderança do fundador da Empresa D, no entendimento de Petry e Nascimento (2009), são fundamentais para alimentar o bom desempenho da empresa, dedicando-se ao máximo no momento em que for desempenhar as tarefas associadas à questão de liderança. Portanto, um bom líder precisa incentivar e valorizar os colaboradores, saber ouvir, ser carismático e também instituir que os funcionários tenham disciplina. Este conjunto de características é o que diferencia um bom líder dos demais.

Em consonância com as ideias do autor, o fundador da Empresa D se destacou no papel de disciplinar os colaboradores e filhos, impondo respeito, mas sem ultrapassar a sua autoridade como chefe. O seu carisma também é algo que realça no perfil de líder, pois quando decidiu iniciar o próprio negócio, começou a motivar os filhos, desde pequenos, para que um dia assumissem a empresa.

BATISTA, J. D. et al. O processo de sucessão nas empresas familiares: um estudo feito em empresas familiares da Região do Sul de Santa Catarina. Revista de Empreendedorismo e Gestão de Pequenas Empresas, v.4, n.3, 2015. 


\section{Processo sucessório}

James (2003) aponta que o processo de sucessão é caracterizado como um momento crítico, por diagnosticar que as empresas, quando realizam este processo, conseguem ter êxito após tal procedimento em apenas $50 \%$ desses empreendimentos. Ricca (2012) destaca que não existe um caminho para que a empresa alcance um bom desempenho. Porém, se não levar em consideração os costumes, crenças, valores da família e a cultura organizacional da empresa, as chances do fracasso se tornam plausíveis. Sousa (2012) defende o quão importante é a preparação do sucessor, fazendo com que os filhos acompanhem o planejamento desde o início. Mas a família precisa estar preparada caso o filho não seja a pessoa escolhida para assumir a empresa.

O Quadro 4 apresenta os motivos pelos quais os fundadores se desligaram totalmente da empresa, a forma como aconteceu o processo sucessório e se este processo foi planejado pelos fundadores.

Quadro 4-Processo Sucessório

\begin{tabular}{|c|c|c|c|}
\hline Empresa & $\begin{array}{c}\text { Motivo da saída do } \\
\text { fundador }\end{array}$ & $\begin{array}{c}\text { Maneira como } \\
\text { aconteceu o processo } \\
\text { sucessório }\end{array}$ & $\begin{array}{c}\text { Este processo foi } \\
\text { planejado? }\end{array}$ \\
\hline A & Aposentou-se & Gradativo & Não \\
\hline B & Foi dirigir outra empresa & Gradativo & Não \\
\hline C & Iniciou outro negócio & Natural & Não \\
\hline D & Foi dirigir outra empresa & Gradativo & Não \\
\hline
\end{tabular}

Fonte: As autoras (2015).

Ao observar o Quadro 4, é possível dizer que todos os 4 (quatro) processos têm algo em comum, como o que motivou o fundador a realizar a transição, como aconteceu este processo e o não planejamento da sucessão.

Conforme esclarecido pelo sucessor da Empresa A, o processo sucessório aconteceu gradativamente, em que o fundador estimulou seu filho mais velho, desde criança, a participar das atividades da empresa. Essa convivência permitiu que quando esse filho já estivesse em idade adulta, o pai fosse delegando algumas responsabilidades até se sentir seguro em deixar o filho assumir por completo as atividades da empresa. O Sucessor I da Empresa A afirma: "[...] desde criança eu ajudava na empresa [...] quando cheguei à idade adulta, meu pai já estava com 
idade [...] de se aposentar e eu [...] fui assumindo as coisas [...] foi sendo gradativa [...]" [grifo nosso].

Esse argumento do Sucessor I da Empresa A corrobora com Lodi (1987), quando menciona que é importante iniciar a transição desde a infância dos filhos no sentido de prepará-los para assumir o comando da empresa no futuro. Desta forma, pode-se dizer que houve um planejamento para o processo sucessório, porém não de forma explícita, apenas no estímulo do contato do filho com o ambiente de negócio de seu pai.

Em consonância com o caso da Empresa $A$, na Empresa D, os filhos também começaram a ajudar nos negócios do pai desde adolescentes. Na Empresa $\mathrm{D}$, os sucessores, desde a adolescência, participavam no período da tarde das atividades da empresa, já que no período da manhã ambos estudavam e, aos poucos, foram se aperfeiçoando, obtendo experiências para futuramente assumir o negócio do pai. Desse modo, gradativamente o pai foi delegando a administração da empresa.

[...] aconteceu de maneira [...] gradativa [...] comecei a trabalhar com 11 anos [...] meu irmão começou com 15 [...] a gente estudava de manhã e trabalhava à tarde, $[\ldots]$ eu já sabia o que [...] ia fazer [...] procurei me aperfeiçoar [...] pra trabalhar na empresa do pai [...] ele tem duas empresas [...] uma factoring [...] e uma construtora [...] onde ele ainda está trabalhando [...] [grifo nosso]. (Empresa D Sucessor II).

É importante frisar que o motivo que estimulou o afastamento do fundador da direção da Empresa D, foi que percebeu a oportunidade de trabalhar em outro negócio, já que os dois filhos mais velhos estavam tomando a frente dos interesses da empresa e ainda tinham estudos e competência para assumir a direção.

A autora Leone (1991), defende que a sucessão pode ocorrer de duas formas: gradativa e planejada. $\mathrm{Na}$ forma planejada, o fundador elabora um plano esquematizando como e quando irá acontecer a sucessão. Já a maneira gradativa, que corresponde à empresa $D$, o fundador primeiramente orienta os filhos sobre como administrar a empresa e após constatar que já estão prontos para assumir o negócio, acontece a transição.

BATISTA, J. D. et al. O processo de sucessão nas empresas familiares: um estudo feito em empresas familiares da Região do Sul de Santa Catarina. Revista de Empreendedorismo e Gestão de Pequenas Empresas, v.4, n.3, 2015. 
Já no processo sucessório da Empresa $\mathrm{B}$, o fundador comandava uma empresa quando resolveu abrir outra no mesmo segmento, porém produzindo outro tipo de produto para evitar a autoconcorrência. Quando o filho iniciou a faculdade, o fundador decidiu que já estava na hora do herdeiro começar a trabalhar na empresa. No início, foram delegadas as tarefas mais simples para o filho, até que depois de um ano de formado, o fundador transferiu a administração da empresa ao filho e foi cuidar do outro negócio.

[...] o meu pai tinha uma gráfica [...] e depois [...] montou esta empresa que eu administro hoje [...] que faz um produto diferente do que ele fazia [...] quando eu comecei a faculdade [...] ele mandou eu vim para a empresa [...] e ele começou a me passar as coisas aos poucos [...] depois de um ano de formado ele me chamou e disse [...] agora é contigo [...] ele continua na outra empresa [...]. [grifo nosso]. (Empresa B - Sucessor II).

Embora a sucessão na Empresa B tenha dado certo e não tenha prejudicado sua posição no mercado, Rodrigues, Resende e Pilatti (2004) alertam que o fato do fundador não estar preparado para escolher seu sucessor pode acabar comprometendo a empresa. Portanto, o patriarca tem a responsabilidade de escolher e ainda preparar seu substituto. Essa ideia foi seguida pelo fundador desta empresa, que soube escolher e orientar seus sucessores.

Conforme relatou o sucessor, a Empresa C estava passando por dificuldades e o volume de vendas diminuiu. Como o fundador estava iniciando outro negócio, estava decidido a encerrar as atividades da empresa. Diante dessa situação, resolveu convidar o filho para assumir a administração da empresa. No processo sucessório, demorou 2 (dois) anos para que o fundador se afastasse definitivamente das atividades, acontecendo de forma que não afetou 0 relacionamento dos dois.

[...] a empresa estava numa baixa [...] as vendas estavam meio paradas, o pai chegou a cogitar a possibilidade [...] de talvez encerrar as atividades e [...] ele tava com um negócio novo [...] aí ofereceu pra eu continuar e [...] eu topei [...] nos últimos dois anos ele $[\ldots]$ já se desligou totalmente [...] e foi de uma forma bem natural [...] não teve nenhum tipo de [...] conflito. [grifo nosso]. (Empresa C).

BATISTA, J. D. et al. O processo de sucessão nas empresas familiares: um estudo feito em empresas familiares da Região do Sul de Santa Catarina. Revista de Empreendedorismo e Gestão de Pequenas Empresas, v.4, n.3, 2015. 
Segundo as informações obtidas pelos sucessores, é possível concluir que o processo de sucessão das 4 (quatro) empresas aconteceu de maneira gradativa. Aos poucos, o tempo ia passando e os sucessores demonstravam maior competência e responsabilidade sobre suas obrigações. Os fundadores ficaram mais confiantes e motivados de que estava chegando a hora dos filhos assumirem as empresas.

A possibilidade de sucessão não aconteceu por motivos de incapacidade devido à idade ou morte dos fundadores, exceto na Empresa $A$. Nas demais Empresas, B, C e D, a sucessão aconteceu devido ao interesse do fundador em empreender em novos negócios. Leone (2005) defende que o processo de sucessão para ser planejado, tem que ser avisado a todos os familiares, inclusive os colaboradores da empresa, informando detalhes de como anda o planejamento do processo. Logo, a autora explica que o processo só é confirmado como sendo planejado se forem informados os detalhes de como está sendo feito o planejamento a todas as partes interessadas.

Das 4 (quatro) empresas entrevistadas, foi constatado que nenhuma teve 0 processo de sucessão, planejado pelo fundador, explicitado aos demais interessados. Porém, no seu intelecto, provavelmente este planejamento ocorreu, mesmo que os sucessores neguem qualquer tipo de planejamento, como observado nas falas dos Sucessores I (Empresa A) e II da Empresa D: "[...] não foi planejada [...] foi uma coisa gradativa não teve um dado momento [...]" [grifo nosso]. (Empresa A - Sucessor I). "[...] à medida que o tempo fosse passando [...] a gente foi subindo [...] até chegar à diretoria." [grifo nosso]. (Empresa D - Sucessor II).

Vale destacar, que a atitude dos filhos, os futuros sucessores, de se dedicarem aos negócios da família desde pequenos é aprovada por Gersick (2006), que apoia a iniciativa dos filhos se interessarem pelos negócios da família. Isso acontece quando, desde criança, já convivem com o pai na empresa, ajudando nas tarefas mais simples, até um dia estarem prontos para assumir o lugar na direção. Isto é confirmado pelo sucessor da Empresa C: "[...] não foi planejado [...] por ele estar começando um negócio novo e [...] teria uma oportunidade melhor de mercado [...] então ele achou prudente [...] se desligar da empresa [...]" [grifo nosso].

BATISTA, J. D. et al. O processo de sucessão nas empresas familiares: um estudo feito em empresas familiares da Região do Sul de Santa Catarina. Revista de Empreendedorismo e Gestão de Pequenas Empresas, v.4, n.3, 2015. 
Desse modo, como forma de treinar os possíveis sucessores, Souza (2012) instrui que os herdeiros tenham experiências em diversos cargos dentro da empresa, proporcionando maior conhecimento sobre as atividades exercidas, pois o domínio sobre cada setor influencia na hora de tomar uma decisão.

\section{Escolha do sucessor}

No momento da escolha do sucessor é aconselhável buscar informações para conhecer quais são as intenções que o possível gestor possui ao assumir a direção da empresa. O grau de parentesco é observado por Petry e Nascimento (2009), mas com experiência e educação formal. Há empresas cujo próprio fundador nomeia seu sucessor, baseando-se no grau de conhecimento e experiências do candidato. Entretanto, não é aconselhável adotar este método de escolha por acarretar possíveis discussões entre os familiares (NOVELLINO, 2010).

No Quadro 5 é possível identificar quem foram os escolhidos pelos fundadores para assumir a administração da empresa.

Quadro 5 - Nomeação feita pelo fundador

\begin{tabular}{|c|c|}
\hline Empresas & Nomeado pelo fundador a assumir a empresa. \\
\hline A & 2 filhos (M) \\
\hline B & 2 filhos $(M)$ \\
\hline C & 1 filho $(M)$ \\
\hline D & 2 filhos $(M)$ \\
\hline
\end{tabular}

Legenda: Masculino (M)

Fonte: As autoras (2015)

Ao observar o Quadro 5, constata-se que em todas as 4 (quatro) empresas, o fundador nomeou os filhos homens, segundo os entrevistados, por acreditar que eles seriam a melhor escolha e serem pessoas de sua confiança.

Bernhoeft (1989) explica que há motivos persuasivos no momento de escolher o sucessor, por ser filho (a), primo (a), sobrinho (a), esposa, as chances de ser escolhido aumentam. Estas ligações familiares com o fundador influenciam diretamente na escolha do sucessor.

BATISTA, J. D. et al. O processo de sucessão nas empresas familiares: um estudo feito em empresas familiares da Região do Sul de Santa Catarina. Revista de Empreendedorismo e Gestão de Pequenas Empresas, v.4, n.3, 2015. 
Os critérios utilizados pelos fundadores para elegerem seus filhos como sucessores, deu-se pelo fato de que desde criança frequentam a empresa, fazendo serviços que não requeriam muita responsabilidade. O Sucessor I da Empresa $A$ afirma que: "[...] eu trabalhava junto com o meu irmão [...] quando a gente era criança, adolescente [...] fazendo tarefas de produção [...]" [grifo nosso].

Vale frisar que na idade adulta, o fundador continuou delegando mais responsabilidades, até se convencer de que os filhos estariam preparados para assumir o lugar dele. É claro que a vontade de os filhos homens em dar continuidade aos negócios da família influenciou bastante na decisão do fundador.

[...] cada ano que passava ele ensinava alguma coisa a mais pra mim $[\ldots]$ até que chegou uma hora que [...] ele falou [...] agora [...] ele tá pronto então ele toca sozinho. [...] desde criança [...] a gente sempre ia [...] pra ajudar o pai [...] eu sempre quis tocar o negócio [...] [grifo nosso]. (Empresa B - Sucessor II).

Fernandes (2012) alega que desde criança, os filhos têm curiosidade em conhecer o trabalho dos pais. É justamente essa curiosidade que os leva frequentarem a empresa. No início, ajudam com tarefas mais simples, depois vão assumindo mais responsabilidades, conhecendo todos os setores da empresa até ocuparem o lugar do pai na administração. "[...] conheci a empresa inteira pra depois assumir uma função [...] até chegar à diretoria. [...]" [grifo nosso]. (Empresa D - Sucessor II).

Outro critério utilizado pelo fundador no momento de escolher o filho como sucessor da empresa estava relacionado com a afinidade e a confiança entre pai e filho, além do interesse nos negócios da família. Ou seja, o fundador optou escolher os familiares com quem tinha mais proximidade, sendo dignos de sua confiança e respeito.

\section{Próximo processo sucessório}

A continuidade da empresa deve ser idealizada pelo fundador, porém a decisão de qual carreira seguir deve ser definido pelo filho e apoiada pelo pai, independente da profissão que ele vá exercer (DONATTI, 1999).

BATISTA, J. D. et al. O processo de sucessão nas empresas familiares: um estudo feito em empresas familiares da Região do Sul de Santa Catarina. Revista de Empreendedorismo e Gestão de Pequenas Empresas, v.4, n.3, 2015. 
O Quadro 6 mostra se as empresas estão preparadas para um próximo processo sucessório, caso ocorra um imprevisto e seja necessária uma sucessão imediata.

Quadro 6 - Planejamento do próximo processo sucessório.

\begin{tabular}{|c|c|}
\hline Empresas & Iniciou o planejando o próximo processo sucessório \\
\hline A & Não \\
\hline B & Não \\
\hline C & Não \\
\hline D & Não \\
\hline
\end{tabular}

Fonte: As autoras (2015).

A respeito das empresas estarem planejando a sucessão da $3^{\underline{a}}$ geração, 0 Quadro 6 revela que as 4 (quatro) empresas entrevistadas ainda não estão desenvolvendo o plano para a próxima sucessão, o que futuramente pode causar transtornos à empresa. "[...] não dá tempo nem de pensar no dia-a-dia quanto mais nisso [...] podemos dizer que não." [grifo nosso]. (Empresa A - Sucessor I). Logo se percebe que na correria do dia a dia, não sobra tempo para imaginar como aconteceria a transição.

As empresas $\mathrm{B}$ e $\mathrm{C}$, pelo motivo de não terem filhos, a possibilidade de os filhos entrarem na empresa fica só na imaginação. "[...] se eu fosse fazer hoje e já tivesse filho [...] eu conversaria mais com ele [...] isso aqui vai ser teu [...] vai te apegar aos poucos, [...] faria [...] trocando ideias." [grifo nosso]. (Empresa B Sucessor II).

Já o sucessor da empresa $C$ relata que, mesmo depois de ter seus filhos, não pensa em se afastar da empresa. Enquanto tiver saúde e condições físicas para trabalhar, continuará trabalhando. "[...] não sei como vai ser os filhos, sucessões futuras "[...] não quero largar os negócios tão cedo enquanto [...] tiver saúde [...] que o meu filho e o meu neto possam estar juntos [...] também [...]" [grifo nosso]. (Empresa C).

O sucessor da empresa $D$ pensa a mesma coisa a respeito de se afastar da empresa. Mesmo não sendo mais jovem, tem condições de dirigir a empresa por mais 15 anos, e caso os filhos não venham a assumir a empresa, tem um gerente que está sendo preparado para assumir seu o lugar na direção.

BATISTA, J. D. et al. O processo de sucessão nas empresas familiares: um estudo feito em empresas familiares da Região do Sul de Santa Catarina. Revista de Empreendedorismo e Gestão de Pequenas Empresas, v.4, n.3, 2015. 
[...] no momento ainda não [...] eu não sou novo [...] mais acho que no mínimo uns $\mathbf{1 5}$ anos todo mundo ainda vai trabalhar [...] a gente tem é a ideia de diminuir a carga de trabalho [...] mais já tem, o meu [...] gerente de vendas [...] que pode assumir meu cargo futuramente [...] tá sendo preparado pra isso [grifo nosso]. (Empresa D - Sucessor II).

É possível concluir que as 4 (quatro) empresas não estão elaborando nenhum planejamento sobre como será a próxima sucessão, além de destacar os sucessores das empresas ( $C$ e D) que não têm vontade de se afastar da empresa. Um estudo de caso feito por Duarte e Oliveira (2010) se identifica com as empresas entrevistadas que alegam não terem planejado a próxima transição por não sentirem o cargo ameaçado pela idade ou pelos filhos.

\section{Considerações finais}

O presente estudo teve o objetivo de conhecer como ocorreu o processo sucessório em empresas familiares. Desta forma, buscou-se compreender quais motivos levaram os fundadores a realizar a sucessão, identificar as características dos fundadores para entender o modelo de gestão das empresas e, por fim, comparar os resultados que evidenciaram que, independente do perfil e do modelo de gestão de cada fundador, todas as 4 (quatro) empresas alcançaram um bom desempenho no processo de sucessão.

Ao conhecer a história de cada empresa, foi possível identificar características que as empresas têm em comum, como o fato de os fundadores nomearem seus filhos para assumirem a direção das empresas. A questão do planejamento do processo sucessório nas 4 (quatro) empresas evidenciou que os fundadores não planejaram as sucessões, elas simplesmente foram acontecendo.

O processo sucessório das 4 (quatro) empresas aconteceu gradativamente. Desde criança, os filhos estavam presentes nas empresas. Com o tempo, identificaram-se com alguma das áreas específicas e resolveram aperfeiçoarem seus conhecimentos, transmitindo, assim, tranquilidade ao fundador quanto à competência e experiência para administrar a empresa. Porém, colocar os filhos em

BATISTA, J. D. et al. O processo de sucessão nas empresas familiares: um estudo feito em empresas familiares da Região do Sul de Santa Catarina. Revista de Empreendedorismo e Gestão de Pequenas Empresas, v.4, n.3, 2015. 
contato com a realidade empresarial do pai pode ser caracterizado com uma forma de planejar a sucessão.

A sucessão só acontece quando um fato ligado ao fundador ocorre, como: falecimento do fundador, aposentadoria ou por doença. Na sucessão de 3 (três) empresas o fator decisivo foi a segurança dos fundadores quanto à competência dos filhos em administrar a empresa, já a sucessão de apenas 1 (uma) empresa aconteceu pela necessidade que o fundador tinha em se aposentar.

Percebe-se uma semelhança entre os motivos que levaram os fundadores a realizar a sucessão, mas é importante frisar a diferença entre os perfis de cada fundador. Um foi considerado centralizador, pois não dividia suas ideias nem comunicava suas decisões. Já o outro era considerado descentralizador, delegando as funções de maior responsabilidade para funcionários de sua confiança, dedicando-se apenas a uma área da empresa. Nas outras 2 (duas) empresas, uma delas tem o fundador com um perfil empreendedor, sempre discutindo suas ideias e propostas com outros colaboradores da empresa, não se importando em ouvir a opinião dos outros. Já o outro, caracterizado como líder, sempre cobra disciplina dos funcionários, principalmente dos filhos.

Como é possível observar, há diversos estilos de se administrar uma empresa, porém, todos os fundadores mantiveram o mesmo foco em relação à maneira de conduzir a sucessão das empresas.

Sobre os filhos continuarem os negócios da família, os 4 (quatro) fundadores optaram por deixar livre, para que filhos decidam que carreira seguir, sem se importar se a próxima sucessão será ou não familiar. Os sucessores já estão cientes que, caso não optem por sucessão familiar, terão que contratar profissionais qualificados para assumirem as empresas. Por enquanto, nenhuma das empresas planeja a próxima sucessão, pelo fato de os fundadores terem vontade e disposição para trabalharem mais alguns anos. Eles não sentem necessidade de encontrar alguém para assumir seus lugares, pois não sentem o cargo ameaçado ou não planejam empreender novos negócios.

A pesquisa apresenta algumas limitações quanto ao número de empresas entrevistadas, que no total foram 4 (quatro). Este indicador é baixo pelo fato de haver restrições por parte das empresas em conceder entrevista, pela exposição de

BATISTA, J. D. et al. O processo de sucessão nas empresas familiares: um estudo feito em empresas familiares da Região do Sul de Santa Catarina. Revista de Empreendedorismo e Gestão de Pequenas Empresas, v.4, n.3, 2015. 
informações internas, além dos diretores dificultarem um possível contato para agendar a entrevista. Com base nos resultados dessa pesquisa, não se pode generalizar estas conclusões sobre a boa gestão do fundador em conseguir realizar o processo sucessório, evitando o fracasso da empresa.

Sendo assim, este estudo retratou o modelo de sucessão de apenas 4 (quatro) empresas. Porém, seria interessante realizar uma pesquisa que abrangesse um número maior de empresas familiares, onde o foco poderia estar nos modelos de gestão e se os sucessores estão dando continuidade aos projetos desenvolvidos pelos fundadores.

\section{Referências:}

ATTUCH, L. O retrato da empresa familiar. Societas Consultoria, n. 507, 13 jun. 2007, p. $48-49$.

BERNHOEFT, R. Empresa Familiar: sucessão profissionalizada ou sobrevivência comprometida. (2.ed.) São Paulo: Nobel, 1989.

CASILLAS, J. C.; VAZQUEZ, A.; DIAZ, C.. Gestão da empresa familiar: conceitos, casos e soluções. São Paulo: Thomson, 2007.

DALBÓ, R. A. As características e o perfil do empreendedor. 2008. Disponível em: < http://www.administradores.com.br/informe-se/artigos/as-caracteristcas-e-operfil-do-empreendedor/24327/>. Acesso em: 22 out. 2012.

DONATTI, L. Empresa familiar: a empresa familiar em um âmbito global. Caderno de Pesquisa em Administração, v. 1, n. 10, p. 56 - 63, 1999.

DONNELLEY, R. G. A empresa familiar. Rae, v. 42, n. 4, p. 161 - 198, 1964.

DUARTE, F. D.; OLIVEIRA, L. R. de. Análise de maturidade de processos sucessórios em empresas familiares. Rege, v. 17, n. 2, p. 135 - 150, 2010.

FERNANDES, A. Pais e filhos: parcerias de sucesso. 2012. Disponível em: $<$ http://www.portalk3.com.br/Artigo/comportamento/pais-e-filhos-parcerias-desucesso>. Acesso em: 22 out. 2012.

FONSECA, L. E. A descentralização da liderança. 2010.

BATISTA, J. D. et al. O processo de sucessão nas empresas familiares: um estudo feito em empresas familiares da Região do Sul de Santa Catarina. Revista de Empreendedorismo e Gestão de Pequenas Empresas, v.4, n.3, 2015. 
Disponível em: < http://www.administradores.com.br/informe-se/artigos/adescentralizacao-da-lideranca/47183/>. Acesso em: 27 set. 2012.

FREITAS, E. C. de; KRAI, L. S. Gestão organizacional em empresas familiares no Vale do Rio dos Sinos. Rege, v. 17, n. 4, p. 387 - 402, 2010.

GALLI, M. Empresa familiar como fortalecer o empreendimento e otimizar o processo sucessório. 125 f. Monografia (Pós-graduação) - Curso de Gestão Empresarial, Universidade Do Extremo Sul Catarinense - Unesc, Criciúma, 2006.

GERSICK, K. E. De Geração Para Geração. 2 ed. Elsevier, 2006.

GIL, A. C. Como elaborar projetos de pesquisa. 3.ed. São Paulo: Atlas, 1996.

GORGATI, V. Os determinantes da estrutura de capital de empresas familiares brasileiras durante os processos sucessórios. $117 \mathrm{f}$. Dissertação (Mestre Em Administração), Universidade De São Paulo, São Paulo, 2000.

GRZYBOVSKI, D.; TEDESCO, J. C. Empresa Familiar $x$ Competitividade: Tendências e Racionalidades em Conflito. Teor. Evid. Econ., v. 6, n. 11, p. 37 - 68, 1998. $<$ http://www.upf.edu.br/cepeac/download/rev n11 1998 art3.pdf $>$. Acesso em: 17 abr. 2012.

IBGE, Instituto Brasileiro De Geografia E Estatística. As Micro e Pequenas Empresas Comerciais e de Serviços no Brasil. 2003. Disponível em: http://www.ibge.gov.br/home/presidencia/noticias/11092003microempresahtml.shtm. Acesso em: 27 set. 2012.

JAMES, I. O processo sucessório nas organizações. 2003. Disponível em: <http://www.canalrh.com.br/mobile/artigo.asp?o=\%7BA1B30936-7D01-48D5-A270B5F02173B3A7\%7D\&a=1>. Acesso em: 27 set. 2012.

LANSBERG, I. Succeeding generations: Realizing The Dream of families in Business. Boston, 1999.

LEMOS, M. de F. M. O processo de sucessão em empresas familiares: Planejamento da troca de comando evita desgastes emocionais e riscos para as empresas. FAE Business, n. 5, p. 40 - 42, 2003. Disponível em: $<$ http://www.fae.edu/publicacoes/pdf/revista fae business/n5/gestao oprocessodesu cessaoemempfamiliares.pdf> Acesso em: 18 abr. 2012.

BATISTA, J. D. et al. O processo de sucessão nas empresas familiares: um estudo feito em empresas familiares da Região do Sul de Santa Catarina. Revista de Empreendedorismo e Gestão de Pequenas Empresas, v.4, n.3, 2015. 
LEONE, N. M. de C. P. G.. A Sucessão não é um tabu para os dirigentes da PME. In.: XV ENCONTRO ANUAL DA ASSOCIAÇÃO NACIONAL DE PROGRAMAS DE PÓS-GRADUAÇÃO EM ADMINISTRAÇÃO, 15., 1991, Belo Horizonte. Anais... Belo Horizonte, 1991, p. $243-257$.

Sucessão na empresa familiar: Preparando as Mudanças para Garantir Sobrevivência no Mercado Globalizado. Editora Atlas, 2005.

. Os duelos (duetos) identificados por ocasião do processo sucessório.

Estratégia e Negócios, v. 1, n. 1, 2008.

LETHBRIDGE, E. Tendências da Empresa Familiar no Mundo. Revista do BNDES, v.7, n.1, p. $1-18,1997$.

LODI, J. B. O Fortalecimento da Empresa Familiar. 2.ed. São Paulo: Pioneira, 1987.

NEVES, J. C. das. A sucessão na empresa familiar: A Estrutura de Governo e o Controlo do Capital: In.: Conferência de Finanças, Universidade Dos Açores, 2001.

NORDQVIST, M.; WENNBERG, K.; BAU, M.; HELLERSTEDT, K. An entrepreneurial process perspective on succession in family firms. Small Business Economics, v. 40, n. 4, p. 1087 - 1122, 2013.

NOVELLINO, A. Como escolher seu sucessor? 2010. Disponível em: $<$ http://www.portaltudoemfamilia.com.br/cms/?p=1056>. Acesso em: 03 nov. 2012.

NUNES, F. F. Centralizador: por que alguns líderes têm esse perfil? 2009. Disponível em: <http://www.administradores.com.br/informese/informativo/centralizador-por-que-alguns-lideres-tem-esse-perfil/23782/>. Acesso em: 03 nov. 2012

OLIVEIRA, D. P. R. de. Empresa familiar: como fortalecer o empreendimento e otimizar o processo sucessório. São Paulo: Atlas, 1999.

PETRY, L. I.; NASCIMENTO, A. M. Um estudo sobre o modelo de gestão e o processo sucessório em empresas familiares. Revista Contabilidade \& Finanças, v. 20, n. 49, p.109 - 125, 2009.

RICCA, D. Empresa Familiar: Sucessão em Conflito Administradores. 2008. Disponível em: $\quad<\quad$ http://www.administradores.com.br/informe-

BATISTA, J. D. et al. O processo de sucessão nas empresas familiares: um estudo feito em empresas familiares da Região do Sul de Santa Catarina. Revista de Empreendedorismo e Gestão de Pequenas Empresas, v.4, n.3, 2015. 
se/informativo/empresa-familiar-sucessao-em-conflito/14747/>. Acesso em: 27 set. 2012.

\section{O papel do carisma e da liderança do fundador nas Empresas}

Familiares. 2012 Disponível em: $<$ http://www.incorporativa.com.br/mostranews.php?id=8741>. Acesso em: 03 out. 2012.

RODRIGUES, M.; RESENDE, L. M.; PILATTI, L. A. Processo de sucessão nas empresas familiares de pequeno e médio porte: o desafio da continuidade. In.: XI SIMPÓSIO DE ENGENHARIA DE PRODUÇÃO - SIMPEP, 11, 2004, Bauru. Anais... Bauru, 2004, p.1 - 8.

SOUSA, A. A. Empresas familiares: a importância do planejamento sucessório. 2012. Disponível em: <http://www.administradores.com.br/informese/artigos/empresas-familiares-a-importancia-do-planejamento-sucessorio/61958/> Acesso em: 12 abr. 2012.

SOUZA, E. da P. de. O desafio da continuidade no processo sucessório em uma empresa familiar: Um estudo de caso de uma indústria moveleira na região norte de Belo Horizonte. 72 f. Dissertação (Mestrado Profissional de Administração) Fundação Pedro Leopoldo, Faculdades Integradas de Pedro Leopoldo, Pedro Leopoldo, 2012.

VENTURA, L. C. O Conselho de Administração na Empresa Familiar. Acionista, Porto Alegre, $2006 . \quad$ Disponível em: $<$ http://www.acionista.com.br/governanca/200706 luciano ventura.htm>. Acesso em: 12 abr. 2012.

YIN, R. K. Estudo de caso: planejamento e métodos. 3.ed. Porto Alegre: Bookman, 2005. 